Check for updates

Cite this: RSC Adv., 2017, 7, 51252

Received 12th September 2017 Accepted 19th October 2017

DOI: 10.1039/c7ra10141d

rsc.li/rsc-advances

\section{Transformable protein-gold hybrid materials serve as supramolecular vehicles for gene delivery $\dagger$}

\author{
Zhenhua Li, Han Ding, Fei Yan, Hongwei Li (D) and Zhijun Chen (iD * \\ Functional DNA cannot pass through plasma membrane of living cells by itself. An efficient non-viral DNA \\ carrier with low cytotoxicity and simple preparation procedure is in high demand. Herein, we describe that \\ protein-gold hybrid nanocubes (PGHNs) could intrinsically recognize DNAs, and transform them into \\ nanoflower-like structures. These supramolecular complexes can be internalized by living yeast cells and \\ allow the coding information of the gene to be transmitted into proteins. PGHN-DNA can be a good \\ model to study DNA-carrier interactions as well as a new carrier for gene delivery research.
}

Vehicles are the key player in gene delivery system, which help to transport genetic materials toward different cells for various purposes..$^{1-3}$ These gene vehicles can be divided into two classes, namely viral ${ }^{4-6}$ and non-viral carriers. ${ }^{7-12}$ Viral carriers exhibit high DNA transfection efficiency. ${ }^{13}$ Nevertheless several disadvantages limit their application in biological and clinical research, such as cytotoxicity, carcinogenicity, and immunogenicity. ${ }^{14-16}$ Non-viral carriers are equally important, which may be partially exempt from the limitations of viral carriers mentioned above. Among them, lipoplexes, cationic lipids, and cationic polymers have been widely explored. ${ }^{17-24}$ However, these traditional non-viral carriers also exhibit certain weaknesses such as low transfection efficiency, toxicity, or complicated preparation procedure. Hence, new generation non-viral carriers with high transformation efficiency, low cytotoxicity, and simple preparation procedure are highly favored.

In this report, we describe an interesting finding that recently reported protein-gold hybrid nanocubes (PGHNs) ${ }^{25}$ showed special gene carrier capability as compared to other gold nanoclusters (Au NCs). ${ }^{26,27}$ PGHNs were cube-like, blue emissive upon UV radiation, and can be readily internalized by living cells. ${ }^{25}$ Herein we described that PGHN can interact with DNA and transform into higher supramolecular structure. Interestingly, the PGHN-DNAs can be up-taken by classical research model yeast Saccharomyces cerevisiae in an efficient manner. PGHNs can be prepared easily and showed good biocompatibility and low cytotoxicity toward Escherichia coli cells. ${ }^{25}$ These transformable protein-gold hybrid materials can serve as supramolecular vehicles for gene delivery in fungi (Scheme 1).

State Key Laboratory of Supramolecular Structure and Materials, Institute of Theoretical Chemistry, International Joint Research Laboratory of Nano-Micro Architecture Chemistry, Jilin University, No.2699 Qianjin Street, Changchun 130012, China.E-mail: zchen@jlu.edu.cn; lihongwei@jlu.edu.cn

$\dagger$ Electronic supplementary information (ESI) available: Additional the experimental section and Fig. S1-S9. See DOI: 10.1039/c7ra10141d
In our previous report, we described that fluorescent PGHNs can be readily internalized by living cells and thus can be used for bioimaging..$^{25}$ PGHN synthesis was briefly as follows, BSA, tryptophan, and $\mathrm{HAuCl}_{4}$ were mixed and $\mathrm{pH}$ of the solution were adjusted to 3.0 , followed by incubation at $30^{\circ} \mathrm{C}$ for $12 \mathrm{~h}$, where the concentration of these compounds were 5,20 , and $1.6 \mathrm{mg} \mathrm{mL} \mathrm{m}^{-1}$, respectively. The product was dialyzed, centrifuged, and stored in $4{ }^{\circ} \mathrm{C}$ fridge before use. Notably, the concentration of $\mathrm{HAuCl}_{4}$ and PGHNs was referred to the concentration of either $\mathrm{Au}^{3+}$ or $\mathrm{Au}$ atoms. The excitation and emission of PGHNs were 395 and $480 \mathrm{~nm}$, respectively. Under UV irradiation ( $365 \mathrm{~nm}$ ), PGHN cubes was blue emissive, which was due to the conjugated Au NCs (Fig. S1 and S2 $\dagger$ ). Although no precise structures of this type of protein-Au NCs available this far, previous researches hinted that proteins were served as capping agents to foster the formation of Au NCs. ${ }^{28-32}$ During the synthesis process, protein-Au NC complexes can be further assembled into higher nano-structures with large sizes depending on the specific conditions. The photostability of PGHNs was determinated using fluorescence measurement as

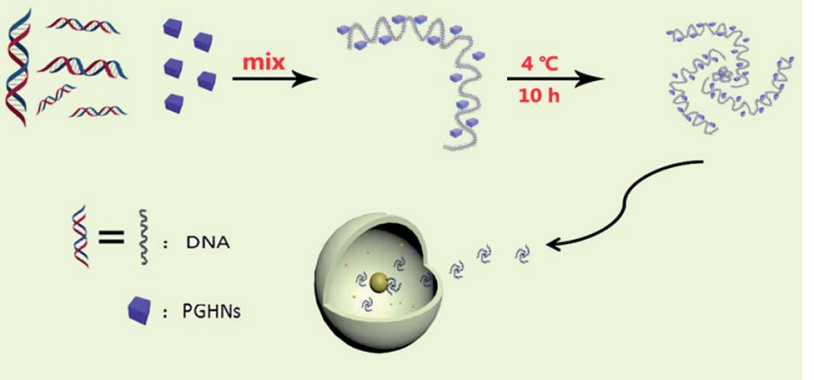

Scheme 1 Schematic presentation of PGHN-DNA assembly and its application in gene delivery. The gray wires and blue cubes stand for DNAs and PGHNs, respectively. 
well as bleaching experiments (Fig. S3 and S4†). Notably, the surface positive charge of PGHNs suggested these materials might interact with negatively charged DNAs. To explore this possibility, plasmid DNA (pGal-sGFP) (Fig. S3 and S5, $\uparrow 100 \mathrm{ng}$ $\left.\mu \mathrm{L}^{-1}\right)$ were mixed with PGHNs $\left(1.33 \mathrm{mM} \mathrm{L}^{-1}\right)$ at different volume ratios for a final volume of $100 \mu \mathrm{L}$, and rotating incubated at $4{ }^{\circ} \mathrm{C}$ for $10 \mathrm{~h}$, and then subjected to agarose gel electrophoresis. The retardation of plasmid DNAs was observed from the gel, indicating that PGHNs interacted with the plasmid DNA (Fig. 1A). This supramolecular interaction can be further optimized via changing the ratio of these two components (Fig. 1A and B). Noteworthy, as PGHN-DNA interaction can be partially damaged in the process due to the harsh condition of electrophoresis, the real number of interacted DNAs toward PGHNs were possibly much higher than that was shown on Fig. 1.

To further investigate the supramolecular interaction between PGHN and DNA, isothermal titration calorimetry (ITC) was applied. PGHNs were titrated towards plasmid DNA of pGalsGFP with initial value $-1.0 \mathrm{kcal} \mathrm{mol}^{-1}$. Following the increased content of PGHNs, the reaction heat was gradually increased, and finally reached $-0.3 \mathrm{kcal} \mathrm{mol}^{-1}$ (Fig. 2A). The thermodynamic parameters were calculated and fit by using least square method. The binding affinity turned out to be $1.42 \times 104 \mathrm{M}^{-1}$ with $\Delta H$ of $-2.79 \mathrm{kcal} \mathrm{mol}^{-1}$ and $\Delta S=8.97 \mathrm{cal} \mathrm{mol}^{-1} \mathrm{deg}^{-1}$. In parallel, BSA instead of PGHNs was also titrated toward the plasmid pGal-sGFP (Fig. 2B), suggesting no interaction between BSA and DNA was occurred. These results indicated that AuNCs of PGHNs might be involved in the PGHN-DNA interaction. How was the supramolecular interaction/assembly occurred? The unique DNA binding property of PGHN triggered us to investigate the co-assembly process of PGHN and DNA.

The supramolecular assembly of PGHN-DNA complex was monitored by using scanning electronic microscopy (SEM). This process was initiated by electrostatic interaction between positively charged PGHNs and negatively charged plasmid DNA. Specifically, $90 \mu \mathrm{L}$ PGHNs $\left(1.33 \mathrm{mM} \mathrm{L}^{-1}\right)$ was mixed with $10 \mu \mathrm{L}$ plasmid pGal-sGFP (100 $\left.\mathrm{ng} \mu \mathrm{L}^{-1}\right)$, to make a final volume of 100 $\mu \mathrm{L}$. The mixture was incubated at $4{ }^{\circ} \mathrm{C}$ for $10 \mathrm{~h}$. The time and concentration effects were investigated. Interestingly, the recognition and co-assembly of PGHNs and plasmid DNA (pGalsGFP) turned out to be a slow and sophisticated process.
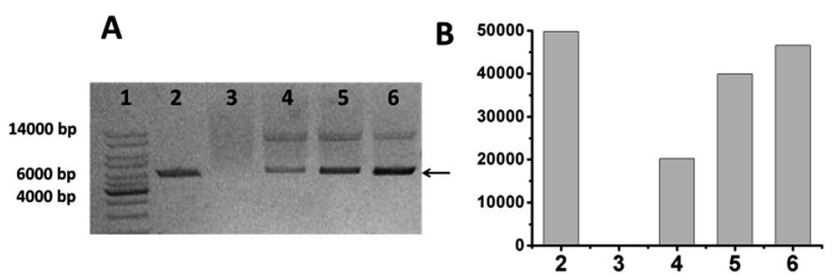

Fig. 1 The binding of pGal-sGFP and PGHNs was analyzed using agarose gel electrophoresis. (A) Lane 1, 1 kb DNA ladder; lane 2, pGalsGFP DNA; lane 3, PGHNs; lane 4-6 represented PGHN-DNA mixture prepared with different volume ratios (the volume of PGHNs was 0 , $100,90,60$, and $30 \mu \mathrm{L}$, respectively, where DNA volume was always 10 $\mu \mathrm{L}$ except for lane $3(0))$. (B) The intensity of the lower DNA band (A: arrow) was quantified.
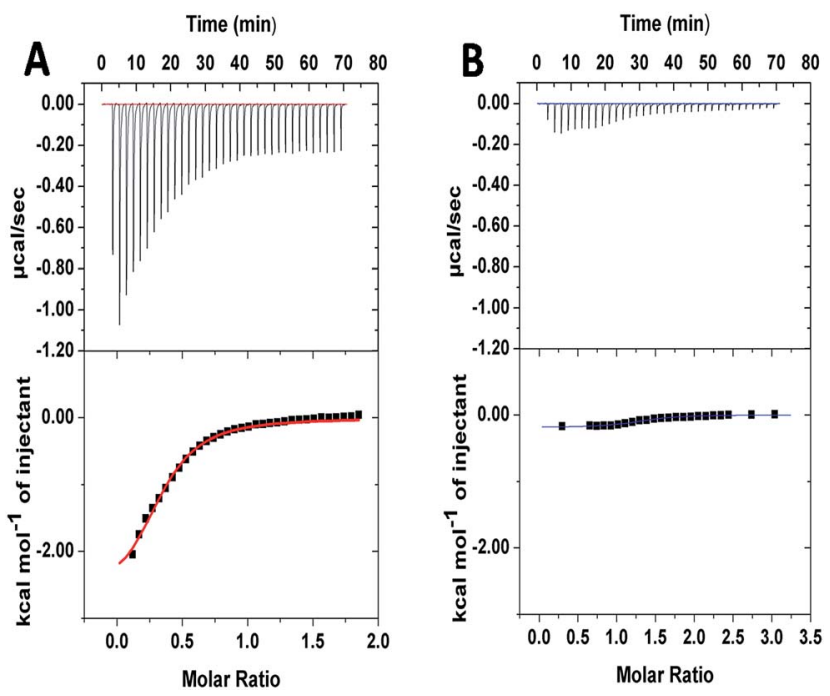

Fig. 2 Isothermal titration calorimetry (ITC) showed the energy associated with a reaction triggered by the interaction between pGalsGFP and PGHNs (A) or pGal-sGFP and BSA (B).

Interestingly, the morphology of PGHN-DNAs gradually shifted from cubic to nanoflower-like structures (Fig. 3). We speculated that DNA may bend and fold into clew-like conformation under the guidance of PGHNs. Notably, during the assembly process, the size of the PGHN-DNAs was gradually increased, shifting from 90 to $500 \mathrm{~nm}$ (Fig. 3A-D). This phenomenon was also supported by the data obtained from Dynamic Light Scattering (DLS) (Fig. S4-S7†). The driving force that triggered PGHN-

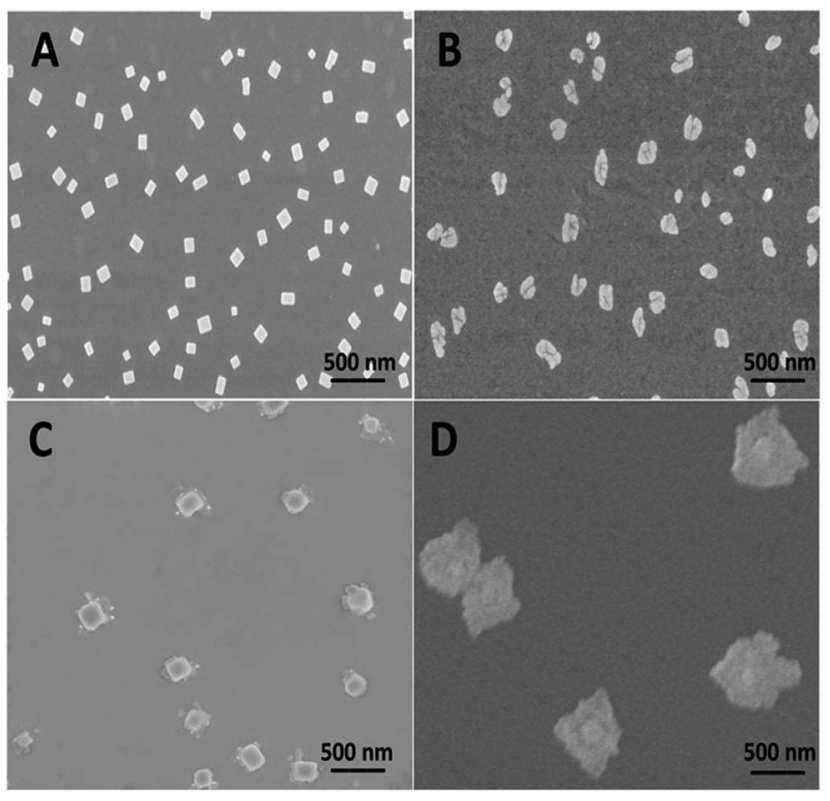

Fig. 3 Morphology characterization of PGHNs and PGHNs-DNAs by using SEM and the time effect on the co-assembly of PGHNs-DNAs. (A) Representative SEM image of PGHNs. (B-D) Co-assembly of pGalsGFP and PGHNs. These two components were mixed for indicated time, $4 \mathrm{~h}(\mathrm{~B}), 6 \mathrm{~h}(\mathrm{C})$, and $10 \mathrm{~h}(\mathrm{D})$. The average size of the nanostructures was approximately $90,130,200$, and $500 \mathrm{~nm}$, respectively. 
DNAs slowly change the structure may be associated with their supramolecular recognition such as electrostatic interaction.

Biocompatibility is a critical concern for gene or all the other type of drug carriers. Cytotoxicity of PGHN-DNAs was evaluated by using both prokaryotic and eukaryotic cells via monitoring their growth curve in the presence of PGHN-DNAs. The yeast cells (S. cerevisiae, BY4741) were inoculated and shaking incubated in YPD media at $30{ }^{\circ} \mathrm{C}$. The $\mathrm{O} / \mathrm{N}$ culture was washed twice by using $1 \times$ phosphate-buffered saline (PBS) buffer and transferred into fresh YPD media. The cells were then re-suspended and the cell density was adjusted to $\mathrm{OD}_{600}=0.1$. These cells were divided into two groups, where one was mixed with $400 \mu \mathrm{L}$ PGHNs, the other with equal amount of $1 \times$ PBS buffer. These two group of cells were shaking incubated at $30{ }^{\circ} \mathrm{C}$. Samples were taken and subjected to $\mathrm{OD}_{600}$ measurement every $2 \mathrm{~h}$, until reaching static station. The cytotoxicity of PGHNs toward mammalian cells was evaluated using Cell Proliferation and Cytotoxicity Assay Kit (Beijing Seajet Scientific, Beijing, China). The hepatocyte cell line LO2 originating histologically from normal human liver tissue was obtained from Key Laboratory of Polymer Ecomaterials, Changchun Institute of Applied Chemistry, Chinese Academy of Sciences. The human cervical cancer cell line Hela was purchased from American Type Culture Collection (ATCC). Two cell lines were cultured in RPMI1640 containing $100 \mathrm{U} \mathrm{mL}^{-1}$ penicillin, $100 \mu \mathrm{g} \mathrm{mL} \mathrm{mL}^{-1}$ streptomycin and $10 \%$ fetal bovine serum. Hela (cancer cells) or LO2 (normal cells) cells were treated with different doses of nanoparticles for 48 and 72 hours, and subjected to CCK- 8 assay for cytotoxicity analysis. The results revealed that PGHNs were noncytotoxic to all the cell lines tested so far (Fig. 4).

The size, morphology, and surface charge of vehicles are important measures to assess the plausibility if they can be internalized by living cells. DNA is strong negatively charged biopolymer, which hinders their crossing of plasma membrane of cells. Notably, during the supramolecular assembly of PGHN-DNAs, the strong negatively charged DNAs were largely neutralized as shown on the zeta potential measurement with final value approaching nearly zero (Fig. S8†). The change of size and surface charge of PGHNs after interacting with DNA suggested a gene carrier possibility of these materials. Altogether, the suitable size, low cytotoxicity, DNA binding capability, and non-viral origin indicated PGHNs might serve as a new type of DNA carrier for gene transformation research.

To investigate the plasma membrane crossing capability of PGHN-DNAs, yeast $S$. cerevisiae BY4741 were used. Yeast was a classical eukaryotic model for biological study, which was very much similar to mammalian cells in terms of subcellular structure and key signaling and metabolic pathways. ${ }^{33,34} \mathrm{~S}$. cerevisiae cells were shaking incubated overnight $(\mathrm{O} / \mathrm{N})$ at $30{ }^{\circ} \mathrm{C}$. $1 \mathrm{~mL}$ of the $\mathrm{O} / \mathrm{N}$ culture was centrifuged and washed 2 times using $1 \times$ PBS buffer. The collected cells were mixed with $400 \mu \mathrm{L}$ PGHN-DNA nanoflowers, transferred to $5 \mathrm{~mL}$ fresh yeast extract
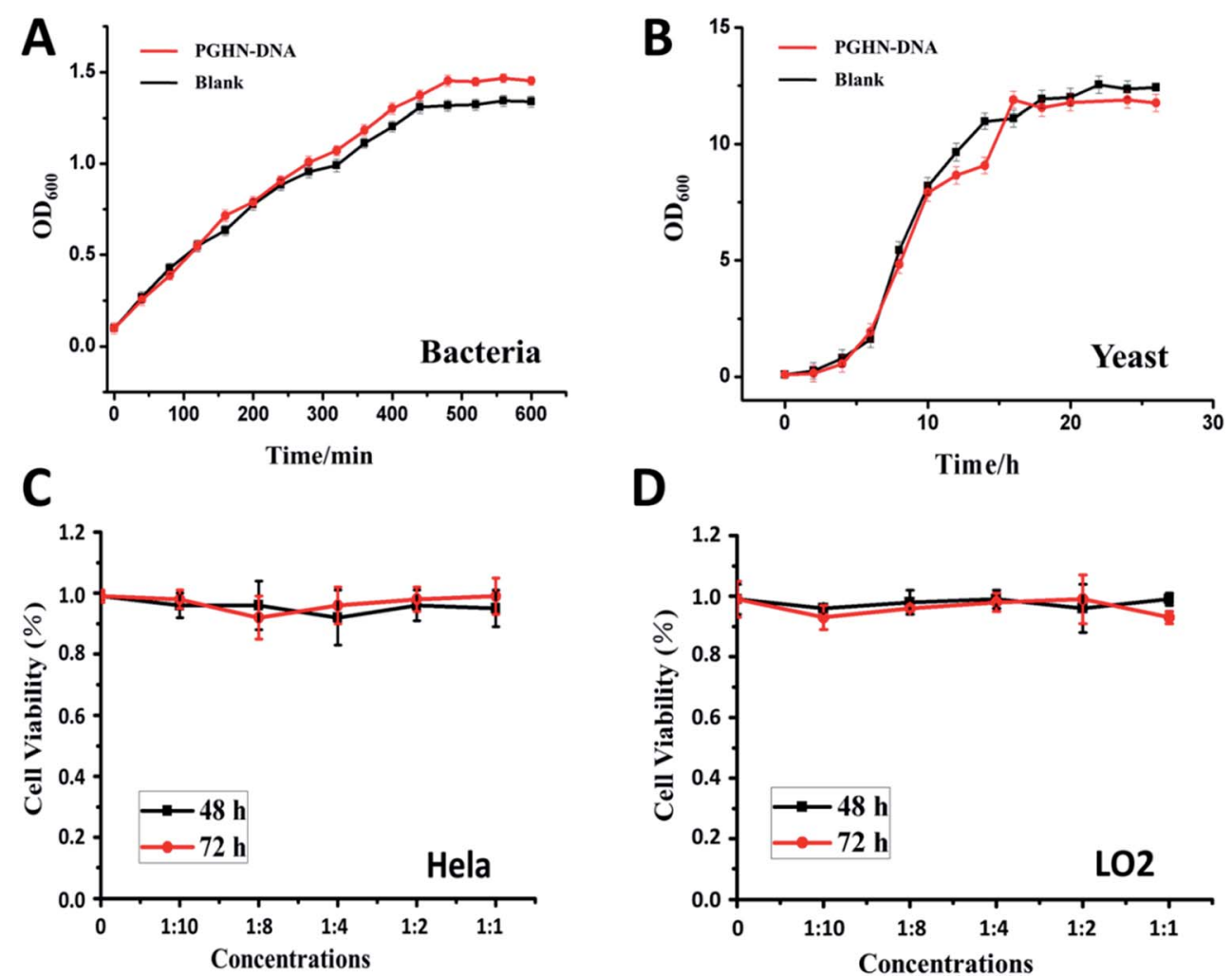

D

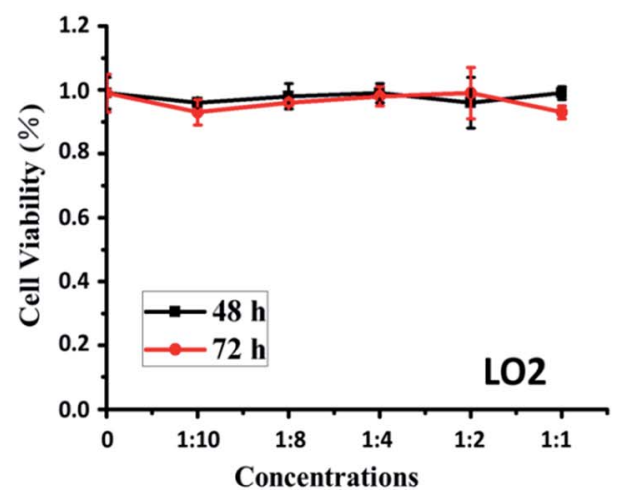

Fig. 4 The cytotoxicity experiments of PGHN-DNAs with different biological research models. The optical density (OD) measurement of the PGHN-DNAs incubated with bacteria (A) and yeast (B) cells. Cell viability measurement of the PGHN-DNAs incubated with cancer (Hela) (C) and normal liver (LO2) cells (D). As shown on the growth curve, PGHN-DNAs did not show a clear observable toxic effect. The black lines represent test group, the red lines represent control group. The value are plotted as mean $\pm \mathrm{SD}(n=3)$. 


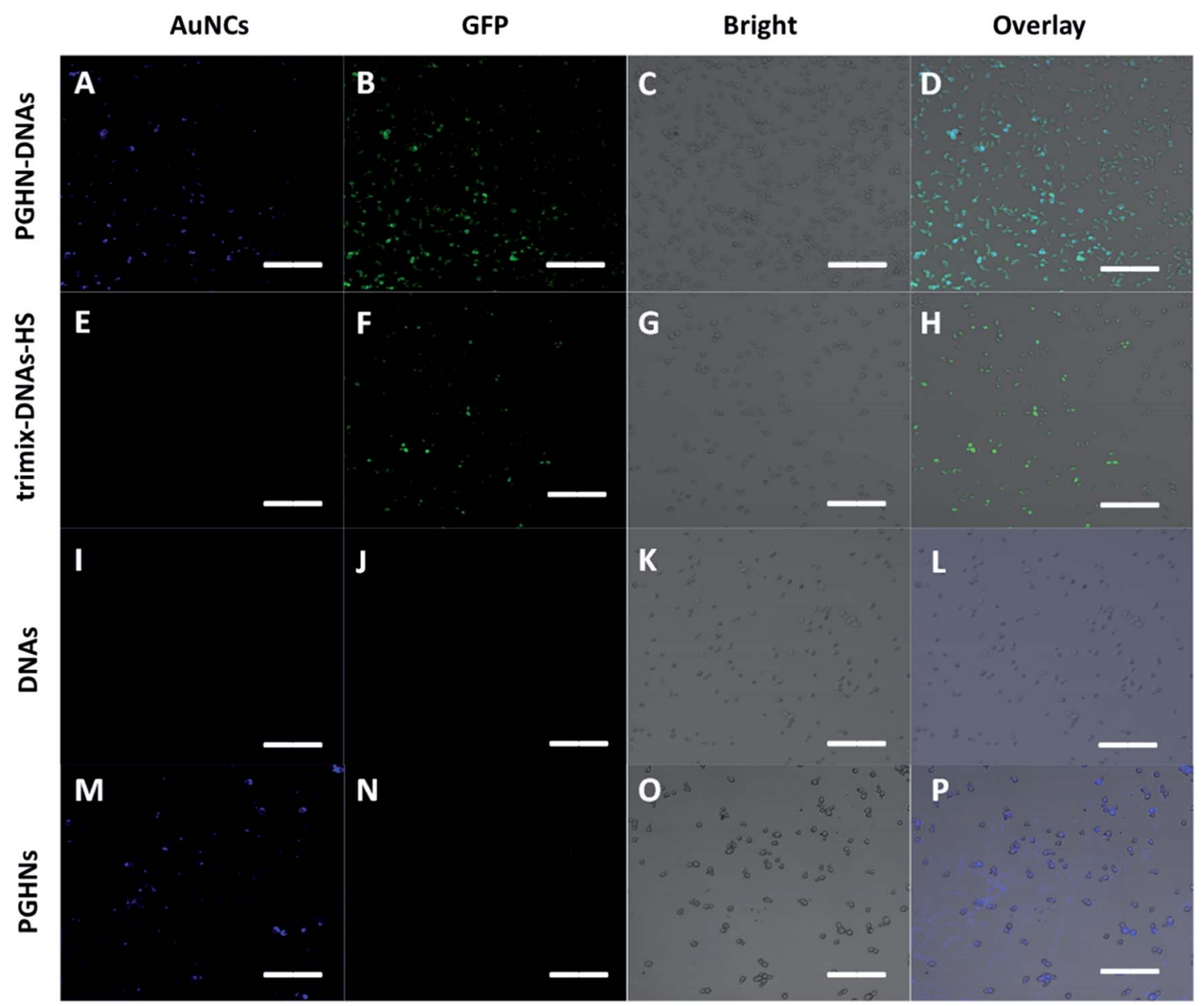

Fig. 5 Fluorescence microscopic images of EGFP expression in yeast cells transfected using different methods, (A-D) referred to DNA transformation by using this new method. (E-H) Referred to DNA transformation by using traditional approach (trimix-heatshock). (I-L) Referred to negative control 1 where pGal-sGFP DNAs were present while PGHNs were absent. (M-P) Referred to negative control 2 where PGHNs was present while pGal-sGFP DNAs were absent. All scale bars were $20 \mu \mathrm{m}$.

peptone dextrose (YPD) media containing $2 \%$ galactose, and then incubated by shaking for $1 \mathrm{~h}$, followed by further shaking incubation at $30^{\circ} \mathrm{C}$ for additional $2 \mathrm{~h}$. Notably, the presence of galactose induced the expression of green fluorescent protein (GFP) which was under the control of Gal promoter (Fig. S5†). Yeast cells in the absence of PGHN-DNA (replaced by $400 \mu \mathrm{L}$ $\mathrm{dH}_{2} \mathrm{O}$ ) were followed the same procedure to serve as negative control. The classical yeast transformation approach (trimixheat-shock) was applied as a positively control. This trimixheat-shock approach can be described briefly as follows, the collected cells from $1 \mathrm{~mL} \mathrm{O} / \mathrm{N}$ culture were mixed with $80 \mu \mathrm{L}$ trimix ( $0.2 \mathrm{M}$ LiAc, 40\% PEG3350, $100 \mu \mathrm{M}$ DTT), followed by sequently adding $4 \mu \mathrm{L}$ ssDNA $\left(10 \mathrm{mg} \mathrm{mL}^{-1}\right)$ and plasmid DNA (4 $\mu \mathrm{g})$. The mixture was incubated at $45{ }^{\circ} \mathrm{C}$ for $45 \mathrm{~min}$, and then transferred to $5 \mathrm{~mL}$ fresh YPD media, followed by shaking incubation at $30{ }^{\circ} \mathrm{C}$ for $2 \mathrm{~h}$. These yeast cells were collected by using centrifugation and then washed twice using $1 \times$ PBS buffer, and then transferred into YPD media containing galactose $(2 \%)$ for additional $2 \mathrm{~h}$ for galactose induction. For fixation, $37 \%$ paraformaldehyde (PFA) were added into cell culture to make a final concentration of $3.7 \%$, followed by shaking incubation at $30^{\circ} \mathrm{C}$ for $30 \mathrm{~min}$. The cells were then washed twice using solution $\mathrm{P}(0.1 \mathrm{M}$ phosphate buffer, $\mathrm{pH} 6.5,1.5 \mathrm{M}$ sorbitol), followed by re-suspending of cells using solution $\mathrm{P}$ containing additional $25 \mathrm{mM}$ DTT and incubation at room temperature for $10 \mathrm{~min}$. The cell samples were mounted on cover slips and subjected to fluorescent microscopic analysis.

Fluorescent microscopic analysis showed that the pGal-sGFP DNA had been successfully uptaken by $S$. cerevisiae cells using this new method. Importantly, the plasmid DNA that entered the cells remained functional as shown by the green fluorescent signals, indicating the induction and expression of GFP (Fig. 5A-D). Significantly, compared to well-established classical trimix-heat-shock approach, this new method showed even higher transformation efficiency (Fig. 5E-H and S9†). In contrast, the negative control group did not show any positive fluorescent signal (Fig. 5I-L), confirming that naked DNA cannot enter the yeast cells under this condition. Moreover, in the absence of DNA, PGHNs can be internalized by yeast cells (Fig. 5M-P), exhibiting blue emission, whereas no green emission was detected in the green channel. Notably, the fluorescent 
pattern of GFP (Fig. 5A-D) and PGHNs (Fig. 5M-P) were slightly different, indicating their different subcellular localization.

\section{Conclusions}

Taken together, as recently emerged new protein-gold hybrid materials, PGHNs can interact with plasmid DNA likely through electrostatic interaction. This process has been investigated by using both agarose gel electrophoresis, ITC, and SEM. The supramolecular co-assembly of PGHNs and plasmid DNA was slow and dynamic. During this course, the size, surface charge, and morphology of the PGHN-DNA complexes were significantly changed. Hence, PGHNs can serve as shapetransformable gene vehicles, which is special and worthy to explore further. Moreover, these complexes showed hardly any toxicity toward both bacteria and yeast cells, indicating a good biocompatibility. Finally, PGHN-DNAs can be readily internalized by yeast cells with high efficiency as compared to the traditional yeast transformation approach. We expect that PGHN-DNA can be a good model to study DNA-carrier interaction as well as new carriers for gene delivery research.

\section{Conflicts of interest}

The authors declare no competing financial interest.

\section{Acknowledgements}

We would like to acknowledge the financial support from the National Natural Science Foundation of China (NSF 21372097).

\section{Notes and references}

1 Y. Tao, E. Ju, J. Ren and X. G. Qu, Chem. Commun., 2013, 49, 9791.

2 F. McCormick, Nat. Rev. Cancer, 2001, 1, 130-141.

3 L. Brannon-Peppas, B. Ghosn, K. Roy and K. Cornetta, Pharm. Res., 2007, 24, 618-627.

4 M. A. Kay, J. C. Glorioso and L. Naldini, Nat. Med., 2001, 7, 33-40.

5 M. A. Zanta, P. Belguise-Valladier and J. P. Behr, Proc. Natl. Acad. Sci. U. S. A., 1999, 96, 91-96.

6 M. Rafalski, A. Ortiz, A. Rockwell, L. C. Van Ginkel, J. D. Lear, W. F. DeGrado and J. Wilschut, Biochemistry, 1991, 30, 10211-10220.

7 M. D. Brown, A. G. Schätzlein and I. F. Uchegbu, Int. J. Pharm., 2001, 229, 1-21.

8 K. Kodama, Y. Katayama, Y. Shoji and H. Nakashina, Curr. Med. Chem., 2006, 13, 2155-2161.

9 B. Zhang, X. Ma, W. Murdoch, M. Radosz and Y. Q. Shen, Biotechnol. Bioeng., 2013, 110, 990-998.
10 T. B. Ren, L. Li, X. J. Cai, H. Q. Dong, S. M. Liu and Y. Y. Li, Polym. Chem., 2012, 3, 2561-2569.

11 S. T. Guo, Y. Y. Huang, W. D. Zhang, W. W. Wang, T. Wei, D. S. Lin, J. F. Xing, L. D. Deng, Q. Du, Z. C. Liang, X. J. Liang and A. J. Dong, Biomaterials, 2011, 32, 4283-4292.

12 X. J. Cai, H. Q. Dong, W. J. Xia, H. Y. Wen, X. Q. Li, J. H. Yu, Y. Y. Li and D. L. Shi, J. Mater. Chem., 2011, 21, 14639-14645.

13 S. Munier, I. Messai, T. Delair, B. Verrier and Y. AtamanOnal, Colloids Surf., B, 2005, 43, 163-173.

14 N. S. Templeton, Biosci. Rep., 2002, 22, 283-295.

15 T. Nagasaki and S. Shinkai, J. Inclusion Phenom. Macrocyclic Chem., 2007, 58, 205-219.

16 T. A. Ratko, J. P. Cummings, J. Blebea, J. Blebea and K. A. Matuszewski, Am. J. Med., 2003, 115, 560-569.

17 P. L. Felgner, T. R. Gadek, M. Holm, R. Roman, H. W. Chan, M. Wenz, J. P. Northrop, G. M. Ringold and M. Danielsen, Proc. Natl. Acad. Sci. U. S. A., 1987, 84, 7413-7417.

18 M. C. P. de Lima, S. Simões, P. Pires, P. Pires, H. Faneca and N. Duzgunes, Adv. Drug Delivery Rev., 2001, 47, 277-294.

19 H. T. Lv, S. B. Zhang, B. Wang, S. H. Cui and J. Yan, J. Controlled Release, 2006, 114, 100-109.

20 S. B. Zhang, Y. M. Xu, B. Wang, W. H. Qiao, D. L. Liu and Z. S. Li, J. Controlled Release, 2004, 100, 165-180.

21 D. Schaffert and E. Wagner, Gene Ther., 2008, 15, 1131-1138.

22 O. Boussif, F. Lezoualc'h, M. A. Zanta, M. D. Mergny, D. Scherman, B. Demeneix and J. P. Behr, Proc. Natl. Acad. Sci. U. S. A., 1995, 92, 7297-7301.

23 C. Rudolph, J. Lausier, S. Naundorf, R. H. Müller and J. Rosenecker, J. Gene Med., 2000, 2, 269-278.

24 S. Y. Wong and J. M. D. Pelet, Proc. Natl. Acad. Sci. U. S. A., 2007, 32, 799-837.

25 H. Ding, D. Y. Yang, C. Zhao, Z. k. Song, P. C. Liu, Y. Wang, Z. J. Chen and J. C. Shen, ACS Appl. Mater. Interfaces, 2015, 7, 4713-4719.

26 L. Shang and G. U. Nienhaus, Acc. Chem. Res., 2017, 50, 387395.

27 J. Xie, Y. Zheng and J. Y. Ying, J. Am. Chem. Soc., 2009, 131, 888-889.

28 G. A. Simms, J. D. Padmos and P. Zhang, J. Chem. Phys., 2009, 131, 214703.

29 J. S. Gebauer, M. Malissek, S. Simon, S. K. Knauer, M. Maskos, R. H. Stauber, W. Peukert and L. Trrurl, Langmuir, 2012, 28, 9673-9679.

30 R. Khandelia, S. Bhandari, U. N. Pan and S. S. Ghosh, Small, 2015, 11, 4075-4081.

31 W. Gu, Q. Zhang, T. Zhang, Y. Li, J. Xiang, R. Peng and J. Liu, J. Mater. Chem. B, 2016, 4, 910-919.

32 J. L. Burt, C. Gutiérrez-Wing, M. Miki-Yoshida and M. JoséYacamán, Langmuir, 2004, 20, 11778-11783.

33 D. Botstein and G. R. Fink, Science, 1988, 240, 1439-1443.

34 D. Botstein and G. R. Fink, Genetics, 2011, 189, 695-704. 